\title{
Uma tradição inventada: a história da escola particular no Brasil, sob a interpretação do intelectual católico Kuno Paulo Rhoden em 1985
}

An invented tradition: the story of the private school in Brazil, under the interpretation of the Catholic intellectual Kuno Paulo Rhoden in 1985

Una tradición inventada: la historia de la escuela particular en Brasil, sobre la interpretación del intelectual católico Kuno Paulo Rhoden en 1985

Eduardo Norcia Scarfoni

Universidade Federal do Espírito Santo (Brasil)

Bolsista de pós-doutorado pela Capes e pela Fapes

http://lattes.cnpq.br/9898180284972399

https://orcid.org/0000-0003-3333-6806

eduardoscarfoni@hotmail.com

Mauro Castilho Gonçalves

Pontifícia Universidade Católica de São Paulo (Brasil)

http://lattes.cnpq.br/5251617595766623

https://orcid.org/0000-0003-1074-8314

mauro_castilho@uol.com.br

\section{Resumo}

Este artigo pretende debater a partir da análise histórica dos Congressos Nacionais de Estabelecimentos Particulares de Ensino (CONEPEs) a concepção de sociedade dos sujeitos presentes nesses eventos dando destaque para a questão da liberdade de ensino no Brasil. Os CONEPEs se iniciam no ano de 1944 sendo organizados a princípio por associações de estabelecimentos de ensino e, posteriormente, pela Federação dos Estabelecimentos de Ensino (FENEN). Focalizaremos especificamente a conferência Retrospectiva histórica da escola particular, proferida pelo padre jesuíta Kuno Paulo Rhoden no XX CONEPE, realizado na cidade de Florianópolis, no estado de Santa Catarina, entre os dias 14 e 18 de julho de 1985 tendo como temática central "Democracia e Liberdade de Ensino". Os dirigentes de estabelecimentos particulares de ensino, considerados aqui como intelectuais, se organizavam e buscavam atuar de maneira conjunta, a fim de se fazerem hegemônicos na educação nacional.

Palavras-chave: Congressos Nacionais de Estabelecimentos Particulares de Ensino (CONEPEs). Ditadura civil-militar brasileira (1964-1985). Kuno Paulo Rhoden. Liberdade de ensino. 


\begin{abstract}
This article intends to discuss from the historical analysis of the national conferences of private educational establishments (CONEPEs) The conception of society of the subjects present in these events giving prominence to the issue of freedom of education in Brazil . The CONEPEs start in the year 1944 being organised initially by associations of educational establishments and subsequently by the Federation of Educational Establishments (FENEN). We focus specifically on the historical retrospective conference of the private school, handed down by the Jesuit priest Kuno Paul Rhoden in the XX CONEPE, held in the city of Florianópolis, in the state of Santa Catarina, between 14 and 18 July 1985 having As a central theme "Democracy and freedom of education". The leaders of private educational establishments, considered here as intellectuals, organized themselves and sought to act in a joint manner in order to make themselves hegemonic in national education.
\end{abstract}

Keywords: National conferences of private educational establishments (CONEPEs). Brazilian civil-military dictatorship (1964-1985). Kuno Paulo Rhoden. Freedom of education.

\title{
Resumen
}

Este articulo pretende debatir a partir del análisis histórico de los Congresos Nacionales de Establecimientos Particulares de Enseñanza (CONEPEs) la concepción de sociedad de los sujetos presentes en esos eventos dando destaque para la cuestión de la libertad de enseñanza en Brasil. Los CONEPEs se inician en el año de 1944 siendo organizados, por la Federación de los Establecimientos de Enseñanza (FENEN). Nos focalizamos específicamente en la conferencia Retrospectiva histórica de la escuela particular, proferida por el padre jesuita Kuno Paulo Rhoden en el XX CONEPE, realizado en la ciudad de Florianópolis, en el estado de Santa Catarina, entre los días 14 y 18 de julio de 1985 teniendo como temática central "Democracia y Libertad de Enseñanza". Los dirigentes de establecimientos particulares de enseñanza, considerados aquí como intelectuales se organizaban y buscaban actuar de manera conjunta, con la intención de hacerse hegemónicos en la educación nacional.

Palabras-clave: Congresos Nacionales de Establecimientos Particulares de Enseñanza (CONEPEs). Dictadura civil-militar brasilera (1964-1985). Kuno Paulo Rhoden. Libertad de enseñanza. 
Em julho de 1985, em Florianópolis, capital do estado de Santa Catarina foi realizado o XX Congresso Nacional dos Estabelecimentos Particulares de Ensino (CONEPE). O evento contou com a participação de representantes de segmentos ligados às escolas particulares, de variadas orientações e interesses. Os CONEPEs, cuja gênese localiza-se na década de 1940, objetivavam debater questões educacionais e o papel das instituições de ensino privado no país. Os anais do evento supracitado, principal fonte de pesquisa, registram, além de outras temáticas, a conferência Retrospectiva histórica da escola particular, proferida pelo padre jesuíta Kuno Paulo Rhoden, à época presidente do sindicato dos estabelecimentos particulares de ensino do Paraná.

Fundamentado em duas obras de referência, Educação e Dependência, de Manfredo Berger, e a dissertação de mestrado A escola particular e a democratização do ensino, defendida por seu irmão João Claudio Rhoden, o conferencista em destaque, expôs o papel fundador do paradigma jesuítico e o método da cronologia como ferramenta para compreender o sentido atribuído à escola particular na configuração da educação nacional. Kuno P. Rhoden exerceu diversas funções durante sua trajetória: foi diretor de colégios na região sul do país, nas cidades de Salvador do Sul (RS), Curitiba (PR) e Florianópolis (SC). Participou como membro efetivo do Conselho Estadual de Educação do Paraná e lecionou na universidade federal deste estado. Sua ação ativa a favor do ensino privado e confessional possibilitou a Rhoden uma ascensão política no meio educacional, o que lhe rendeu a presidência do Sindicato de Estabelecimentos Particulares de Ensino do Paraná e sua participação na Federação Nacional dos Estabelecimentos de Ensino (FENEN).

Em 1985 esse dirigente se volta para uma Retrospectiva histórica da escola particular que foi a primeira temática apresentada no XX CONEPE com o objetivo de fazer esse retrospecto com "qualidade". Kuno Rhoden ${ }^{1}$ foi o responsável por apresentar esse histórico e iniciou esse trabalho lembrando da escola jesuíta do padre Vicente Rijo ${ }^{2}$ em 1549 com a escola de ler e escrever. Considerada por ele o início de toda a história da educação brasileira, se estendendo, essa forma de ensino aos 4 primeiros séculos. Para demostrar toda a periodização da história da escola particular, o autor se utiliza do livro de Manfredo Berger, Educação e Dependência, que separava os períodos dessa maneira:

1- Monopólio Jesuítico - 1549 a 1759.

2- Ensaio de secularização - 1759 a 1808.

3- Reconstrução e academização - 1808 a 1834.

4- Abandono público e fase áurea da iniciativa particular - 1834 a 1889.

5- Reformas consecutivas e desconexas - 1889 a 1930.

6- Ensaio de democratização e adaptação as condições brasileiras 1930 a 1961.

7- Expansão de um sistema educacional alienado da realidade - 1961 a 1971.

8- Aproximação às necessidades da sociedade global - 1971 ... (ANAIS, 1985, p.87).

\footnotetext{
${ }^{1}$ Foi diretor do Colégio Catarinense em Florianópolis e também integrou o Conselho Estadual de Educação.

2 Irmão e depois Padre Jesuíta. Ingressou na Companhia de Jesus em Coimbra, em 16/11/1545, para auxiliar leigo e Irmão coadjutor. Veio para o Brasil com o Padre Manoel de Nóbrega em 1549, na comitiva do Governadorgeral Tomé de Souza, sendo ordenado padre logo depois de sua chegada na Bahia. Quinze dias depois de desembarcar, já tinha aberto uma escola de ler e escrever, ensinando aos mamelucos (filhos de portugueses com índias). Disponível em: <http://www.al.sp.gov.br/noticia/?id=263489 >. Acesso em: 06 mar. 2017.
} 
Afirmava que essa periodização oferecia algumas vantagens, pois levava em consideração a moldura administrativa e constitucional e o tipo de escola dominante. Rhoden utiliza-se também, quase que integralmente, do capítulo $3^{\circ}$ da dissertação de mestrado de João Claudio Rhoden ${ }^{3}$, para elaborar esse histórico do sistema educacional brasileiro. Essa dissertação estava publicada e a venda nesse XX CONEPE.

Rhoden inicia a análise histórica pelo monopólio jesuítico com a vinda de seis jesuítas em 1549 sob a orientação de Manoel de Nobrega para realizar a conversão dos indígenas a fé católica pela catequese e instrução. A organização escolar do Brasil-colônia estaria ligada diretamente com a política colonizadora dos portugueses e a vinda desses jesuítas seria a primeira educação escolar do Brasil. A finalidade da Companhia de Jesus não se restringia ao ensino primário também surgiram escolas de ler e escrever e colégios. As escolas de ler e escrever eram estritamente voltadas para a alfabetização, os seminários eram voltados para o ensino da moral, filosofia e línguas. Já os estudos de teologia, medicina e direito eram realizados na universidade jesuítica de Coimbra e restringiam-se às famílias mais influentes.

Para financiar suas escolas e colégios os jesuítas organizaram fazendas, engenhos e comércios, atividades que dessem lucro para sua manutenção. Essa preocupação se dava, segundo Rhoden, pela falta de recursos públicos destinados da metrópole para a colônia. Esses recursos se existissem iriam quase que exclusivamente para as escolas jesuítas.

Com a expulsão dos jesuítas em 1759 por Marques de Pombal devido a influência do iluminismo, o sistema educacional da colônia virou um caos segundo o autor. Os jesuítas já tinham estabelecido 17 colégios, 10 seminários, 25 residências e 36 missões pelo Brasil e todos foram fechados sem uma outra organização que os substituísse. Até a chegada da corte portuguesa em 1808 abriu um espaço no ensino colonial com apenas algumas escolas e aulas régias sendo fundadas, consideradas pelo autor, insuficientes de número, qualidade e resultados.

Já com a corte portuguesa no Brasil, Dom João VI instala a primeira biblioteca pública, cria escolas superiores e incentiva o ensino primário e o secundário. Essa política se seguiu com Dom Pedro I e as Regências. Porém muitas das leis destinadas a educação ficaram no papel devido à falta de meios técnicos e financeiros. Rhoden considerava que essas medidas tomadas pelo governo português favoreceram a academização do sistema educacional brasileiro com a criação das faculdades de direito voltadas para a elite.

Com o ato adicional a Constituição de 1834 ficaram transferidas para as províncias a tarefa de administrar o ensino primário e secundário e as escolas superiores com o poder central. Essa medida aprofundou o abandono do primário e do secundário já que as províncias não estavam preparadas para organizar o ensino. Nas palavras do autor:

O resultado não poderia ser senão um completo abandono do ensino primário e secundário. Esta consequência era inevitável pois as províncias sem as mínimas condições não poderiam organizar e, muito menos, desenvolver um sistema escolar de ensino. Sem condições técnicas e financeiras e sem qualquer orientação comum o ensino vegetava de acordo com a situação própria de cada província (ANAIS, 1985, p. 95).

Apesar desse abandono alguns colégios surgem e em 1837 se cria o colégio modelar Pedro II para o ensino secundário. Algumas escolas normais e outras escolas secundárias também iniciam suas atividades, porém sem sucesso devido à falta de verbas, instalações e pessoal.

Em contraste com esse abandono do ensino secundário público a iniciativa particular teria seu auge, segundo Rhoden, de 1860 a 1890 nas escolas secundárias. Os jesuítas voltam

\footnotetext{
${ }^{3}$ Diretor do Colégio Anchieta, na cidade de Porto Alegre, no estado do Rio Grande do Sul.
} 
em 1842 quando outras ordens religiosas haviam fundado escolas. A fundação dessas escolas confessionais não católicas (metodistas e presbiterianos) iniciam a difusão de ideias pedagógicas americanas pela sociedade brasileira. A reforma da instrução pública em 1854 teria dado as condições necessárias para a iniciativa privada ficando a cargo do governo sua fiscalização e controle. Em 1858 surge o que chamam de primeiro colégio feminino, o colégio Nossa Senhora do Patrocínio fundado por freiras francesas da congregação de São José de Chambéry na cidade de Itu no estado de São Paulo, mostrando, segundo Rhoden, um avanço quando as questões do preconceito contra a mulher.

Com a proclamação da república em 1889 o ensino entraria em um período de consecutivas reformas, sendo que cada uma com tendências totalmente distintas. Para o autor isso mostrava um desnorteamento com a questão do sistema educacional e exemplificava afirmando que a primeira Constituição de 1891 teria adotado a forma de administrar o ensino do Império. A físcalização e controle das escolas superiores e secundárias eram de responsabilidade da união e as primárias, comerciais, normais, técnicas e profissionais de reponsabilidade dos estados e municípios. As escolas particulares primárias eram de responsabilidade dos estados e as secundárias da união e estados.

Essa primeira Constituição não teria atribuído recursos nem quantidade e qualidade das escolas. Com isso se consolidava a separação entre o sistema de formação das elites e da educação popular, os estados e municípios não tinham a condição necessária para manterem o ensino primário, comercial e profissional repetindo o que acontecia no Império.

Essa dupla função dos sistemas ampliou os organismos estaduais, porém sem criar nenhuma conexão entre eles, ou seja, não havia articulação. Nas palavras de Rhoden:

Os sistemas estaduais, pelas razoes mais obvias, não se articulavam convenientemente com o sistema federal, alargando-se cada vez mais o divórcio entre o sistema de instrução popular e o sistema de instrução de elites (ANAIS, 1985, p. 98).

Essa situação do sistema educacional abriu precedentes para as diversas reformas que se sucederam no período. O próprio Ministério da Instrução Pública criado em 1890 foi extinto em 1891 voltando apenas em 1930 com o nome de Ministério da Educação e Saúde Pública. Esses anos todos a educação ficou sem um órgão próprio mostrando a falta de interesse pela educação, sendo considerada um problema de menor importância.

Em 1930 ocorre uma mudança no panorama educacional devido as transformações da sociedade brasileira com a industrialização, o populismo, a urbanização. Esse novo cenário segundo Rhoden abriu espaço para o início de um processo de democratização. A nova Constituição de 1934 estabelecia a necessidade de criação de um plano nacional de educação com as formas de financiamento do ensino oficial, as competências dos níveis de ensino, a obrigatoriedade do ensino primário e veio tornar facultativo o ensino religioso. A Constituição de 1937 absorveu todos esses itens e incluiu o ensino profissionalizante obrigando as indústrias e sindicatos a criarem escolas para os filhos de seus empregados.

Com essas mudanças na sociedade e a transformação no sistema de educação voltado para o controle do Estado, Rhoden o define como um "instrumento oficial de manipulação das classes menos favorecidas", pois agora esses estavam incorporados nesse novo modelo com a criação das escolas técnicas e profissionais. O público dessas escolas não seriam as classes dominantes.

Já em 1945 com a democratização e a nova Constituição de 1946 de "espirito liberal e democrático" não modificaram imediatamente o ensino que continuava centralizado no Ministério da Educação. Essa descentralização viria apenas em 1961 com a aprovação da Lei de Diretrizes e Bases (LDB). 
Com o aumento da classe média e da demanda por ensino, houve uma queda na qualidade da educação. Os recursos escassos não permitiam acompanhar o crescimento dessa demanda. Nessa ocasião, em 1948, que se inicia o projeto da LDB cujo debate, entre os defensores do ensino público e do ensino particular durou treze anos, sendo aprovada apenas em 1961. Apesar de chegarem ao consenso algumas questões continuavam sem solução como a democratização e a desintelectualização do sistema educacional. Mesmo com todas essas mudanças Rhoden acreditava que o mundo do trabalho ainda continuava desvinculado do ensino, ou seja, o ensino ainda estava distante da prática.

Já com a golpe civil-militar em 1964 o autor afirmava que algumas questões do ensino ainda não haviam sido resolvidas como a dualidade da educação, que apesar de amenizada ainda existiam. E por isso em 1971 se tem a nova reforma do ensino básico mudando e elevando o ensino de $1^{\circ}$ grau para oito anos e três anos para o $2^{\circ}$ grau visando à formação profissional. Considerada por Rhoden uma "boa reforma", porém com a demanda de recursos muito elevados o que não permitiu que ela fosse devidamente implementada.

As reformas de uma maneira mais geral não teriam alcançados seus objetivos pois, para o autor, o país ainda continuava com 12 milhões de crianças fora da escola, ou seja, a realidade da educação brasileira continuava sendo de problemas e de uma não democratização efetiva do ensino.

Após esse breve relado do histórico da educação de uma maneira mais geral, Rhoden inaugura uma segunda parte do trabalho que diz respeito a características da ação educacional da escola particular. Voltado ao pioneirismo da escola particular o autor ressalta que o momento era de perseguição aos particulares, não reconhecendo seu valor e as contribuições que deram ao desenvolvimento da sociedade brasileira. Essa argumentação nos leva a perceber a intencionalidade de pressionar o poder público e criar uma coesão entre os dirigentes presentes nesse XX CONEPE.

Voltando aos jesuítas Rhoden relembra que a educação na colônia e todo suporte para o ensino foram exclusivamente particulares embora a igreja estivesse ligada ao Estado. E passando esse período afirmava que por trás dos grandes movimentos de educação tiveram como maioria líderes da iniciativa privada. As renovações educacionais também teriam ocorrido primeiro nos particulares. E apesar de todos esses benefícios a sociedade a perseguição a escola particular estaria voltando, em suas palavras:

Combatida, desprezada, controlada ou simplesmente ignorada e não menos submetida a exigências, quando não absurdas, pelo menos inúteis e desorientadoras, a escola particular caracterizou-se, no decorrer dos séculos, como uma presença assídua, sempre lutando, sempre procurando o seu lugar. Até parece que, quanto mais combatida, como nos tempos do Marques de Pombal; dos albores da República, com a sistemática perseguição do positivismo que visava principalmente combater a igreja, com as lutas quase terríveis do tempo Dom Vital com o seu grande centro de líderes cristãos, de 1920 até encontrar na década de trinta a figura ímpar de Leonel França, SJ, mais floresceu e se engrandeceu, chegando precisamente nesse período conturbado da educação brasileira a alcançar o seu período áureo, do qual hoje ainda se beneficia, embora estejamos vivendo mais uma vez angustias de uma quase extinção, ao que tudo indica, desejada por alguns setores, quer do governo, quer da sociedade, reacendendo-se o debate encarniçado da escola pública única e gratuita, contra a escola particular, paga pelos pais, que já pagaram o seu imposto para a sustentação da escola pública... Parece que o vexame está voltando! (ANAIS, 1985, p. 116). 
Com a disputa pelo espaço na educação brasileira sendo acirrada, devido ao início das movimentações pela nova constituição, esses dirigentes das escolas particulares tinham que ressaltar seu valor perante a sociedade, e radicalizando o discurso conseguiriam uma unidade maior do setor para se prevalecer nesse momento.

E para isso precisavam de representatividade, tópico seguinte pronunciado por Rhoden, que afirmava que em poucos momentos a escola particular teve participação efetiva e expressiva nas decisões nacionais. Quando essa participação ocorria ela não era eficaz. Internamente, nos meios comunitários, as escolas confessionais tinham muita representação, porém a escola confessional estava perdendo espaço para a escola particular com padrões empresariais. E essa mudança de caraterística administrativa e de ideologia teria aprofundado esse vazio de representação.

Essa argumentação de Rhoden nos mostra uma disputa interna dentro da iniciativa privada na educação, alguns dirigentes de colégios confessionais eram contrários a uma escola mais empresarial, caso do autor, que estivesse preocupada com o lucro e uma administração mais profissional, a escola-empresa. A escola empresarial tinha sua representatividade, porém não era essa a mesma que Rhoden gostaria devido a seus princípios ligados ao jesuitismo, considerado por ele um elemento negativo na representatividade.

Por causa desse vazio, considerado pelo autor, a escola particular deveria investir na formação de lideranças políticas para primar pelos seus objetivos. Rhoden considerava que a escola deveria estar voltada para a sociedade não meramente para o lucro, como algumas escolas empresariais, e afirmava que o projeto da escola particular no Brasil nem sempre tinha ficado claro voltando-se muitas vezes para grupos privilegiados.

Finalizando seu trabalho Rhoden afirmava que esse histórico da educação brasileira não deveria desanimar os congressistas mas deveria sim levar a propostas concretas e animadoras de atuação. Para fechar sua fala Rhoden relembra um discurso de W. E. Forster, em 1870, primeiro ministro da Inglaterra que afirmava:

O primeiro problema é: como dar a todo o país boas escolas! Ao tentar resolve-los, os honrados membros do Parlamento, dos dois partidos, reconhecerão que devemos obedecer a certas diretrizes. Não podemos esquecer o dever dos pais, nem nossos deveres junto aos eleitores e aos que pagam taxas.... Ao construir, devemos cuidar de não destruir o que foi feito.... Para atingir o objetivo almejado devemos gastar o mínimo possível de recursos públicos e ter o máximo empenho para não infligir danos as boas escolas existentes.... Nosso objetivo é completar o sistema voluntario atual, preencher vazios, não aplicar recursos públicos onde desnecessário e buscar, tanto quanto possível ajuda dos pais, recebendo cooperação de homens de boa vontade que queriam auxiliar seus semelhantes.... Devo dizer ainda que todo o possível deve ser feito, rapidamente; da oferta imediata da educação elementar depende nossa prosperidade industrial. É inútil tentar oferecer educação técnica aos nossos operários, sem educação elementar; trabalhadores sem educação - e muitos dos nossos o são, terrivelmente, não tem aptidões e, se os deixarmos por mais tempo nessa condição, apesar de suas energias e determinação, eles serão ultrapassados na competição internacional. Da rapidez dessas medidas dependerá também, creio piamente, o bom e seguro funcionamento de nosso sistema eleitoral... Sou dos que não esperariam o povo educar-se antes de receber poder político; se tivéssemos aguardado tanto, teríamos esperado muito pela educação; mas agora, que lhes demos força política, não devemos 
deixar de dar-lhes educação. Há questões que exigem respostas, problemas a resolver e eleitores ignorantes não tem competência para tanto. Desse provimento rápido da educação depende o poderio nacional. As comunidades civilizadas do mundo inteiro estão se reunindo e sendo medidas por suas forças; se pretendermos manter nossa posição entre os homens de nossa posição entre os homens de nossa raça e as nações do mundo, devemos contrabalançar nosso pequeno número aumentando a força intelectual de cada indivíduo... (ANAIS, 1985, p. 124).

A educação deveria ser voltada para a sociedade e a escola particular era o marco para isso. Colaborando com o desenvolvimento não só intelectual dos indivíduos, mas também com a prosperidade nacional. Nesse sentido o autor considerava que a história das escolas particulares deveria ser sempre estudada e relembrada para fortalecer esse setor de ensino.

Conclui-se que Rhoden, articulado numa rede de interesses e desafios postos pelos grupos privados e confessionais de ensino, numa conjuntura de desgaste político da ditadura civil-militar, elaborou essa releitura do papel e da ação dos católicos no campo do ensino, baseada na invenção e manutenção de tradições como práticas reguladas e aceitas com vistas a inculcar valores e normas. Sobre tradição inventada vale destacar as palavras de Hobsbawn (2012):

Por tradição inventada entende-se um conjunto de práticas, normalmente reguladas por regras tácida ou abertamente aceitas; tais práticas, de natureza ritual ou simbólica, visam inculcar certos valores e normas de comportamento através da repetição, o que implica, automaticamente, uma continuidade em relação ao passado.

A tradição construída e inventada por esses dirigentes ressaltava o histórico do ensino particular como um sujeito ativo no desenvolvimento educacional brasileiro sempre colaborando para seu crescimento. A concepção de sociedade imbricada nesse histórico nos faz pensar sobre a relação social dos grupos ali presentes e a influência que esses gostariam de adquirir nesse novo momento de construção da sociedade, com fim da ditadura civil-militar.

Kuno P. Rhoden por ser um padre jesuíta era parte integrante de uma rede de relações que condicionava determinados sujeitos para pensar de maneira parecida ao que estavam propondo para a nova democracia brasileira. Apesar das críticas as escolas meramente empresariais, que também compunham o CONEPE, a defesa do interesse da educação privada, seja ela confessional ou não, de uma maneira mais geral está presente, pois o momento era o de construção dessa nova democracia com disputas internas, entre os grupos do ensino privado (confessionais e leigos), e externas, aos grupos contrários aos benefícios dados as escolas privadas.

Apesar dessas diferenças internas, os grupos presentes no setor educacional privado conseguiam chegar a um consenso, utilizando como uma de suas táticas os CONEPEs, como maneira de se reunir, debater, se fazer mais representativo e coeso perante a sociedade e suas mudanças.

\section{Referências}

BERGER, Manfredo. Educação e Dependência. 3.ed., Rio de Janeiro: Difel, 1980.

CONGRESSO NACIONAL DOS ESTABELECIMENTOS PARTICULARES DE ENSINO, 20, 1985, Florianópolis. Anais... Florianópolis, 1985. 
HOBSBAWM e RANGER, Eric J. Terence. A invenção das tradições.10.ed.,São Paulo: Paz e Terra, 2015.

RHODEN, João Claudio. A escola particular e a democratização do ensino. Curitiba: Rosário, 1985.

SCARFONI, Eduardo Norcia. Os Congressos Nacionais dos Estabelecimentos Particulares de Ensino (CONEPEs) e a hegemonia da iniciativa privada na educação nacional (1964- 1985). 2017. Tese. (Doutorado em Educação: História, Política, Sociedade) - Pontifícia Universidade Católica de São Paulo, 2017. 